\title{
Erratum zu: Business Transformation im digitalen Kontext
}

Olaf Rupprecht, Martin Adlung und Almuth Bibow

Erratum zu:

Kapitel 10 In: M. A. Pfannstiel und P. F.-J. Steinhoff (Hrsg.),

Der Enterprise Transformation Cycle, https://doi.org/10.1007/978-3-658-22694-7_10

Wir machen darauf aufmerksam, dass die jetzt zur Verfügung gestellte Fassung sich von der zunächst veröffentlichten Fassung unterscheidet. Ursache dafür ist, dass aufgrund eines Versehens die Firmenzugehörigkeit des Autors Olaf Rupprecht im Kapitel 10 falsch genannt wurde. 